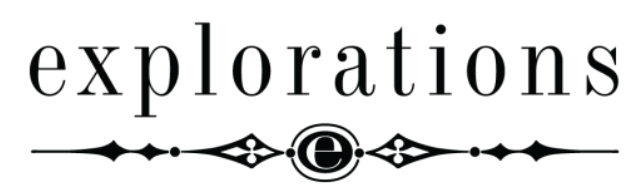

Explorations: A Journal of Language and Literature

\title{
Cultural Barriers in Equivalence - The English Localization of the Video Game Wiedźmin 3: Dziki Gon
}

DOI: 10.25167/EXP13.19.7.6

\author{
Piotr Maziarz (University of Rzeszów) \\ ORCID: 0000-0002-0820-1072 \\ Debora Onik (University of Rzeszów) \\ ORCID: 0000-0001-6901-4636
}

\begin{abstract}
With every passing day, video games are becoming increasingly popular, not only in Poland but also worldwide. As a consequence, a tendency has emerged among the biggest international companies to localize their digital products in an attempt to appeal to their target audience, and thus increase income. The following paper addresses the issue of equivalence in the English localization of the Polish video game Wiedźmin 3: Dziki Gon. More specifically, the authors conduct a comparative analysis of the Polish jokes, puns, songs, customs and other cultural references identified in the corpus, and their target language localizations. Finally, the paper discusses to what extent, if at all, the source and target language versions are equivalent in terms of linguistic, humorous and cultural implications..
\end{abstract}

Key words: localization, translation, equivalence, layers of localization, video game translation

\section{INTRODUCTION}

Although localization as a term functioning within Translation Studies was discussed and analysed by researchers at the very beginning of the $21^{\text {st }}$ century, only latterly has it gained an increasing interest as a translation phenomenon (Maumeviÿienè 2012, 109). The said interest most probably eventuates from the rapid development of technology and computer software, and the fact that the video gaming industry constitutes a bigger market, and therefore generates more income, than the movie and music industries combined (Vierra and Vierra 2011, 100). Wiedźmin 3: Dziki Gon (The Witcher 3: Wild Hunt) substantially contributed to the success of the video gaming industry by receiving 79 various awards, earning over 15 times more income than Wiedźmin 2: Zabójcy Królów

Explorations: A Journal of Language and Literature, 7 (2019), pp. 45-57 
(Witcher 2: Assassins of Kings) and 60 times more than the first game from the trilogy within three years of the game's release. The authors of the present paper are of contention that Wiedźmin 3: Dziki Gon constitutes a suitable example for analysis not only due to the fact that it is replete with humour, folklore and cultural references, but also because the game in question has been localized into fifteen different languages, and therefore proves to be an excellent case for studying the equivalence of culturally-bound elements and reference.

\section{GLOBALIZATION, INTERNATIONALIZATION, LOCALIZATION AND TRANSLATION}

Before discussing the notion of equivalence in localization, however, it is instructive to provide an approximation of the aforementioned concept, so as to facilitate reception of the empirical part of the paper. The term localization, the core notion of the discussion presented herein, accounts for one of the integral elements of a particularly complex multi-stage phenomenon, namely the GILT industry (the appellation itself is an acronym for - as hinted by the subheading - Globalization, Internationalization, Localization and Translation). Each of the said phenomenon's constituents plays a vital role in achieving something that is the aim of every modern company: a considerable increase in so-called return on investment, which is oftentimes referred to in its abbreviated form as ROI (DePalma 2006, 15).

Generally speaking, globalization constitutes an umbrella term encompassing both internationalization and localization, as it is a "business strategy (not so much as an activity) addressing the issues associated with taking a product to the global market which also includes world-wide marketing, sales and support" (Schäler 2008, 197). As may be inferred from the definition provided, globalization revolves around the process of adapting a specific local or regional product - whether it be a tangible good such as a mobile phone or an intangible one such as a mobile application - to the standards and, most importantly, the needs of the global market. ${ }^{1}$

Before a given product can be released onto the global market, it needs to be localized. $^{2}$ However, there is one more step that needs to be undertaken prior to the commencement of the latter, namely internationalization. The notion in question may be defined as the "process of designing software so that it can be adapted to different languages or regions" (Laxström et al. 2017, 209). On the whole, internationalization involves implementation of specific technical modifications to the internal structure of a given product, so as to separate culturally marked elements, and consequently facilitate the localization process thereof into various languages. The pivotal role of internationalization in the GILT industry is particularly stressed by The Localization

\footnotetext{
1 Interestingly enough, Microsoft Corporation's definitions of globalization and internationalization differ slightly from the ones quoted in the present paper. By implication, what is described herein as globalization, the said company defines as internationalization and vice-versa (Anastasiou and Schäler 2010, 14). This phenomenon is particularly intriguing given the fact that Microsoft Corporation localizes its products into a plethora of diversified languages - with Windows 8 being localized into over 200 languages and Windows 10 having 111 language packs. https://docs.microsoft.com/en-us/windows-hardware/manufacture/desktop/ available-language-packs-for-windows [Last accessed: 20.10.2019]

${ }^{2}$ Or, at least, ought to be in order to maximise the chances of increasing a company's profits by gaining the socalled "soft benefits" (Lynch 2006, 45).
} 
Industry Standards Association (hereinafter referred to as LISA), which claims that, while generalizing somewhat, localization of a product that is not internationalized may demand twice as many resource from a company (Anastasiou and Schäler 2010, 13).

As regards the last two constituents of the GILT acronym, translation and localization are so similar in terms of their scopes of reference that sometimes they are used as synonyms (Gambier 2010, 412). This is why it is necessary to point out that certain quite important, albeit very subtle differences exist between the two terms. That being said, translation revolves around "the replacement of textual material in one language (SL) by equivalent textual material in another language (TL)" (Catford 1965, 20). As may be inferred from the quotation provided, it is the textual information encapsulated in a given document that is of main concern in the process of translation. Localization, however, constitutes a slightly more complex phenomenon, as it focuses on the "linguistic and cultural adaptation of digital content to the requirements and locale of a foreign market, and the provision of services and technologies for the management of multilingualism across the digital global information flow" (Schäler 2007, 157). What links these two definitions is the fact that both translators and localizers deal with adaptation of textual content to a given locale - "the language and culture variety natural of a particular geographic region" (Bernal-Merino 2014, 35). What accounts for the afore-mentioned difference, on the other hand, is the fact that translation "does not necessarily deal with digital material whereas localization is always happening in the digital world" (Schäler 2008, 196). ${ }^{3}$ That being said, software localizers work throughout the majority of their time, if not always, with multimodal files which comprise not only text and graphics but also, as in the case of videogames and the examples analysed herein, audio and video.

\section{LAYERS OF LOCALIZATION}

Given the fact that the examples provided in the following paper are to a great extent marked culturally, it is necessary to approximate here the notion of layers of localization. Chroust $(2007,860)$ believes that localization constitutes a multi-layered phenomenon which has to be performed on "different levels of increased comprehensiveness and cultural dependence", with higher levels being highly contingent on all of the lower levels of localization subordinate thereto:

\footnotetext{
${ }^{3}$ This is most probably the reason why the term localization is deemed as a hypernym for the term translation (Munday 2008, 191). Certain scholars contend that for this particular reason translation ought to be removed from the GILT acronym, and even if it is to remain, it ought to be positioned at the very end, since the words that come last in acronyms are of least significance in human perception (Lakoff and Johnson 2003, 132).
} 


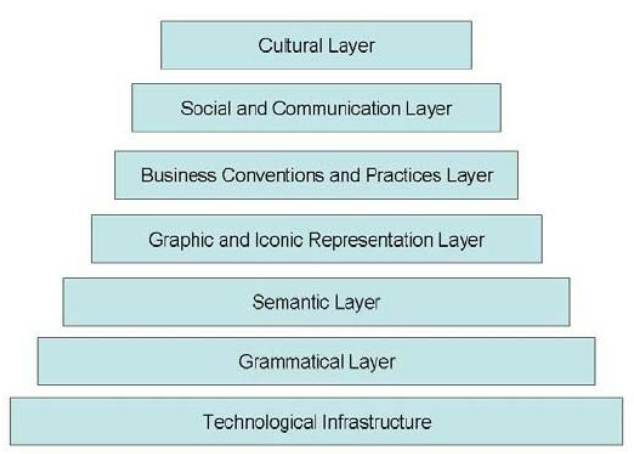

Fig. 1. Layers of localization (Chroust 2007, 860)

The first of the seven layers - which accounts for the foundation of the entire process - is called the Technological Infrastructure (Barbour and Yeo 1996). This layer is particularly vital in the early process of internationalization, since all preparations of technical and organizational natures - whether they be, to name just a few, separation of textual material from the code of a given digital product, reservation of adequate storage space for localized texts or appropriate coding of non-standard characters inherent to certain more exotic languages - have to be meticulously planned prior to the commencement, or at the very least at the beginning, of the entire project.

The Grammatical and Semantic Layers are connected to each other. The Grammatical Layer focuses on translation - or, to be precise, modification - of highly standardized computer-supported textual content. Chroust $(2007,860)$ also postulates that "typically in literary texts variations of expressions are good style, in system oriented domains uniform, standardized texts are to be preferred in order to avoid ambiguity and confusion".

As for the Semantic Layer, it pertains to differences in usage between technical and everyday language, expressiveness thereof and various abbreviations that are employed therein. Given that the said layer is, as the appellation itself seems to indicate, concerned primarily with semantics, it is considered to be the domain of linguistic issues that are mostly tackled by human, rather than computer, language translators.

The Graphic and Iconic Representation Layer refers to the alteration or removal of graphic content that potentially may be culturally problematic or even controversial in certain locales. Such content includes, but is not limited to, gestures, symbols, pictures, animations, voice-acting, subjects of taboo, or even, in certain very conservative countries, colors. Of course, the said layer also deals with addition of the aforementioned elements to the final version of a product in order to appeal to the target audience, and hence increase the profits.

The Business Conventions and Practices Layer, being the least important layer as far as the present paper is concerned, pertains to organizational aspects of a localizer's job - a topic that is, regrettably, not broached whatsoever by the research in question. Notwithstanding, these facets refer to business practices that may differ drastically in various locales, and hence may eventuate in miscommunications, or even conflicts and alienation (Krishna et al. 2004). 
The Social and Communication Layer revolves around a very peculiar kind of communication, namely a unidirectional communication from a medium (digital software) to a human (user). This layer capitalises on implementation of culturally appropriate expressions that, inter alia, address, greet and answer the user in such a way, so as to create software - and the interface thereof - that is characterised by "good behaviour, observation of etiquette and politeness, subservience, helpfulness, and the sensitivity of an intuitive, courteous butler" (Miller 2004).

The Cultural Layer located at the very top of the model proposed by Chroust (2007, 860 ), constitutes the most complex notion as far as the linguistic implications thereof are at issue. This particular state of affairs eventuates from the fact that the layer in question deals with translation and localization of humour, metaphors, jargon, and other culturally bound references that rarely, if at all, have direct one-to-one equivalents in target cultures, and therefore also target languages (Bourges-Waldegg and Scrivener 1998). What makes this issue even more problematic is the fact that, according to Chroust (2007, 867), "context-information will often be lost during localization" of such expressions, thereby resulting in rather unamusing target language renditions that oftentimes are, regrettably, devoid of the meaning and connotations encapsulated by their source language equivalents. Lastly, the importance of the said layer is emphasized by the fact that it draws on the peculiarities of the remaining six layers - hence it requires from a translator or localizer a tremendous amount of not only purely linguistic skills but also practical and cultural knowledge of at least two not infrequently entirely different locales.

\section{CORPUS AND METHODOLOGY}

As regards the corpus subjected to analysis in the present research, one may deem it as being somewhat unusual in terms of content. This eventuates from the fact that the said corpus does not only comprise written texts per se (like, for instance, bestiary, or advertisements and witcher contracts posted on in-game notice boards) but also takes into consideration various dialogues uttered by game characters, or rather by the actors who provide voices for them (in, for example, conversations, songs, riddles, etc.). Therefore, the game itself - that is the base game Wiedźmin 3: Dziki Gon and its two expansion packs: Serca z Kamienia (Hearts of Stone) and Krew $i$ Wino (Blood and Wine) - and everything that is either written or said therein, accounts for the corpus of the following research.

Nevertheless, given the enormity of the game and the space limitations of this paper, it is necessary to stress the fact that only a few examples of potentially problematic localizations are scrutinized herein. To better visualize the size of the corpus analysed, however, it ought to be emphasized that the script of the campaign of the base game alone includes over 450000 words - which is four times more than an average number of words in a typical novel. ${ }^{4}$ As regards the said campaign, it ought to take approximately 50

\footnotetext{
${ }^{4}$ Insofar as the authors' knowledge is concerned, this is the only official piece of data related to, due to lack of a better expression, the "linguistic facet" of the game. Given that the research at issue focuses on the game in its entirety rather than on just a single part of it, the said information serves as the baseline for and is followed by a tentative attempt to estimate the full size of the entire corpus.
} 
hours to finish it without performing any additional activities. ${ }^{5}$ If one wants to complete the entire game (each campaign, secondary quest, contract etc.), together with the abovementioned expansion packs, one ought to be able to do so in more or less 200 hours. Therefore, an assumption may be made that the corpus in question consists of at least, in great approximation, 1000000 words.

As regards the methodology employed in the research, it revolves around the notion of comparative analysis, which focuses on "the explanation of differences, and the explanation of similarities" between at least two divergent yet somewhat interconnected phenomena (Adiyia and Ashton 2017, 1). In the present paper, the phenomena in question refer to the selected examples of the Polish versions of in-game songs, jokes, play-onwords and Slavic customs, as well as the translations, or rather localizations, thereof into the English language and, most importantly, the English culture. Inasmuch as the empirical part is concerned, the discussion pertaining to the data extracted from the corpus in question is divided into two stages. Firstly, the authors present both the Polish and English language versions of the afore-mentioned examples selected from the corpus and, subsequently, provide meticulous descriptions of the contexts in which the said corpus data occurred in the game under scrutiny. The second stage involves the performance of in-depth analyses on the examples in question with the purpose of identifying whether or not they may be classified as equivalents. Effectively, the authors investigate and compare potential similarities and differences between linguistic, humorous, cultural and other various kinds of implications evoked by the Polish examples and their English localizations. The results yielded by the said analyses constitute a point of reference for the formulation of conclusions regarding the relation between the notions of equivalence and localization in the last section of the paper.

\section{BRIEF DESCRIPTION OF THE GAME}

Wiedźmin 3: Dziki Gon constitutes a direct continuation of Wiedźmin and Wiedźmin 2: Zabójcy Królów video games developed and published by CD Projekt company. The trilogy also resumes the events of Wiedźmin: Pani Jeziora - the last book in the six-volume-long Wiedźmin fantasy novel saga written by Andrzej Sapkowski. ${ }^{6}$ The game itself belongs to the action role-playing game (hence the abbreviated form RPG) genre which - contrary to other genres like first person shooters, strategies or simulators of various types - focuses predominantly on immersive storytelling. In such games, players can assume the role of a given protagonist and, by exercising not infrequently morally doubtful decisions that may have an enormous impact on the game's world, and therefore also on the game's ending, actively participate in the creation of the character's story. In Wiedźmin 3: Dziki Gon, players once again are given the possibility to control the titular witcher, Geralt of Rivia who is a monster hunter by profession. The plot of the

\footnotetext{
${ }^{5}$ The last number constitutes a median of the results of the polls conducted by HowLongToBeat amongst 258 people who completed each and every achievement - and thus tackled every activity available - in the game. The said results are available under the following link: https://howlongtobeat.com/game.php?id=40171 [Last accessed: 01.10.2019]

${ }^{6}$ Knowledge of the said books or the two preceding parts of the trilogy, however, is not a necessary prerequisite to the understanding of the examples analysed herein.
} 
game revolves around the protagonist's desperate attempts to find and save his adopted daughter, Cirilla. Despite the fact that the action of the game takes place in an entirely fictional world, players not infrequently may encounter a plethora of so-called easter eggs - events, items or jokes that constitute humorous references to pop-culture, show business, literature, historical figures and events, or even cultural rituals and longforgotten customs. Such references oftentimes may be, and in fact indeed are particularly problematic for translators, as is visualized by the examples provided in the present paper.

\section{PRACTICAL ANALYSIS OF THE SELECTED EXAMPLES}

The analysis conducted on the corpus yielded a few particularly problematic cases insofar as localization and equivalence are concerned. As regards Chroust's model, the most significant differences between the selected target language localizations and their respective source language equivalents are visible in the Semantic, Graphic and Iconic Representation, and Cultural Layers.

The first example to be analysed is a ritual prayer. It is said by Pellar, a folk healer, who performs the ritual, and a mob that has gathered around him in the hope of meeting the souls of their dead relatives. Table 1 provided below contains the source text and its English localization, together with the number of syllables in each line and the rhyme schemes:

\begin{tabular}{|c|c|c|c|}
\hline Source text & \multicolumn{2}{|c|}{$\begin{array}{c}\text { Syllables } \\
\text { and rhyme } \\
\text { schemes }\end{array}$} & English localization \\
\hline \multicolumn{4}{|l|}{ Part I } \\
\hline $\begin{array}{l}\text { Czym jest życie? Sami wiecie. } \\
\text { Krótką męką na tym świecie. } \\
\text { To, co po nim następuje, } \\
\text { Każdy z nas sam decyduje. } \\
\text { Zaraz zjawią się przodkowie, } \\
\text { Co ich dręczy, każdy powie. } \\
\text { Czy gotowiście na swady? } \\
\text { Przybywajcie! Już czekamy! } \\
\text { Zaczynajmy tedy Dziady! }\end{array}$ & $\begin{array}{l}8 \mathrm{a} \\
8 \mathrm{a} \\
8 \mathrm{~b} \\
8 \mathrm{~b} \\
8 \mathrm{c} \\
8 \mathrm{c} \\
8 \mathrm{~d} \\
8 \mathrm{e} \\
8 \mathrm{~d}\end{array}$ & $\begin{array}{l}7 \mathrm{a} \\
7 \mathrm{a} \\
7 \mathrm{~b} \\
6 \mathrm{~b} \\
8 \mathrm{c} \\
8 \mathrm{c} \\
7 \mathrm{~d} \\
7 \mathrm{~d} \\
7 \mathrm{~d}\end{array}$ & $\begin{array}{l}\text { What is this life? Well ye know... } \\
\text { Fleeting torment ere we go. } \\
\text { What comes next, once life subsides... } \\
\text { Man his own fate decides. } \\
\text { Soon will rise thy dead, thy buried... } \\
\text { Each will say by what they're harried. } \\
\text { Will ye grant these souls reprieve? } \\
\text { We're prepared to end their grief! } \\
\text { Let's begin Forefathers' Eve! }\end{array}$ \\
\hline \multicolumn{4}{|l|}{ Part II } \\
\hline $\begin{array}{l}\text { Kto z was wietrznym błądzi szlakiem, } \\
\text { Nie opuścił tego świata, } \\
\text { Tego lekkim, jasnym znakiem, } \\
\text { Przyzywamy! Zaklinamy! } \\
\text { Czy się mylę? Dobrze słyszę? } \\
\text { Duch przerywa nocy ciszę! } \\
\text { Niechaj kądziel płonie w żarze! } \\
\text { Niechaj duch nam się pokaże! } \\
\text { Niechaj duch zabierze głos, } \\
\text { Wnet poznamy ducha los! }\end{array}$ & $\begin{array}{l}8 \mathrm{a} \\
8 \mathrm{~b} \\
8 \mathrm{a} \\
8 \mathrm{c} \\
8 \mathrm{~d} \\
8 \mathrm{~d} \\
8 \mathrm{e} \\
8 \mathrm{e} \\
7 \mathrm{f} \\
7 \mathrm{f}\end{array}$ & $\begin{array}{l}7 \mathrm{a} \\
7 \mathrm{~b} \\
6 \mathrm{a} \\
7 \mathrm{~b} \\
7 \mathrm{c} \\
8 \mathrm{c} \\
8 \mathrm{~d} \\
8 \mathrm{~d} \\
7 \mathrm{e} \\
7 \mathrm{e}\end{array}$ & $\begin{array}{l}\text { Ye who wander on the gale, } \\
\text { Ever caught in this world's thrall, } \\
\text { See this sign, gentle, pale, } \\
\text { Ye we summon! Ye we call! } \\
\text { Hark! A sound I hear! 'Tis right? } \\
\text { A spirit breaks the still of night! } \\
\text { Burn the incense ever higher! } \\
\text { Spirit, join us 'round the fire! } \\
\text { Spirit - speak! This time is yours! } \\
\text { Tell us of your ghostly woes! }\end{array}$ \\
\hline
\end{tabular}

Table 1. Ritual prayer. 
Although the authors of the present paper are of the contention that the above example - and, frankly speaking, the entire game itself - is localized most accurately, there are a few discrepancies between the source and target texts that need to be addressed. First of all, the said localization proves to be problematic on three of the above-mentioned layers. Regarding the Cultural Layer, the source text constitutes a reference to Adam Mickiewicz's Dziady (the complete version of the book was translated into English as Forefathers' Eve by Charles Kraszewski in 2017) - a famous four-part poetic drama that constitutes a significant work of Polish classical literature. Due to the fact that no one-to-one - or even a relatively close - cultural target language equivalent of the said custom exists in the target culture, and the fact that archaic Slavic traditions are not that common in the modern world, the localizers decided to translate the source text and the message encapsulated therein into English, rather than to tailor it to suit a typical American or British custom. As a consequence, the source and target language texts are equivalent in terms of their meaning but the latter is, sadly, not localized into the target culture at all. In order to reverse the situation - namely, to localize the scene at the expense of literal equivalence - Peller could be juxtaposed with three witches from Macbeth who performed a similar ritual (as they too summoned apparitions, however, for different purposes) over a bubbling cauldron. By implication, a reference to Dziady by Adam Mickiewicz would be replaced with a reference to William Shakespeare's Macbeth - and thus both versions of the video game would contain a reference to great poetic works which are particularly significant in their respective cultures. There is one problem, though.

Such substitution would be possible had it not been for the Graphic and Iconic Representation Layer, namely the fact that a player has to actively participate in the said quest by protecting Peller and the mob from various monsters that are accidentally awakened by the ritual performed in the middle of the marshes. As a result, players see how the folk healer looks (his clothes), how he is animated (gestures, body movements, facial expressions), what happens around him (the huge bonfire in the middle of the gathering, reappearing ghosts), and how the mob reacts throughout the entire ritual. Therefore, substitution of the described custom with any other, even if similar, ritual from a different culture would require a dramatic interference in the characters' animations, thereby generating not only huge costs, both in terms of money and time, but also resulting in lack of equivalence between the source and target texts.

As regards the purely linguistic aspect of the analysed localization, that is the Semantic Layer, the localization slightly diverges from the source text in the seventh and eighth line of the first part (see Table 1). According to the source text, Peller asks the people if they are ready for the meeting and subsequent conversation with their dead relatives, and the mob replies that indeed they are waiting for them. In the English translation, however, Peller asks the mob if they want to relieve the dead from any evil, and the people reply that they are ready to put an end to their eternal torment. The eighth line of the English localization is particularly interesting, as it accounts for a good example of an over-interpretation - it implies that the mob has the power to end the suffering of the souls of their loved ones, who somehow are stuck in-between the worlds of the living and the dead. Consequently, the respective source and target lines are not equivalent, as no mention of such power can be found in the source text. 
Lastly, it is worth drawing attention to the form of the prayer and various peculiarities thereof; namely the number of syllables in each line and the rhyme scheme. As regards the former, in the source text nearly $90 \%$ of all lines consist of 8 syllables, whereas this is reduced to about one-fourth in the target language version. The rhyme schemes are also dissonant, particularly at the very end and in the middle of the first and second parts respectively. Nevertheless, such cosmetic changes may be viewed as an unavoidable "necessary evil", since sometimes one has to partially sacrifice the aesthetic form in order to save meaning and maintain equivalence.

The second example - a description of a painting provided by a merchant at a market - is also especially interesting insofar as the Graphic and Iconic Representation and Cultural Layers are concerned. The Polish version of the description goes as follows:

Zarówno samce, jak i samice wijów beauclairskich, są wyjątkowo drapieżne. Choć na ogół polują w grupie, autorowi tego niezwykłego dzieła udało się uchwycić pojedynczego osobnika, szykującego się do ataku. Warto również zwrócić uwagę na łowcę, który, choć przecież musi sobie zdawać sprawę $\mathrm{z}$ grożącego mu niebezpieczeństwa, z kamienną twarzą wyczekuje na właściwy moment, by zaatakować.

The source text was rendered into English in the following manner:

Both male and female Beauclair centipedes are formidable predators. The beasts prefer to hunt in packs, yet the author of this extraordinary work was able to capture a lone specimen, preparing to attack. Cast your eye on the hunter, who, though fully aware of the danger, wears a look of cold determination on his face as he awaits the optimal moment to strike.

It is imperative to draw attention here to two characteristic features of the said texts. Firstly, both of them address a specific scene from an animal's life - in this case the hunt of a huge carnivorous centipede. Secondly, the texts are stylised in such a way as to mimic a text that one might hear in an educational or documentary programme. The differences between the source and target language texts are so minor that one could accept the English version as a proper localization. The problems, however, arise when a player approaches the merchant in-game and hears her voice. In the Polish version of the game the said merchant is dubbed by Krystyna Czubówna, one of the Polish most famous television narrators who has voiced-over a vast amount of educational and documentary programmes. If one combines the afore-mentioned features of the analysed texts with the fact that it is being read by Krystyna Czubówna, one finds a humorous reference to Polish culture which puts a smile on faces of many Polish players. Regrettably, the English version of the game lacks such an effect, as the merchant in question was dubbed by a regular voice-over actress. Inasmuch as localization is at issue, the said humorous reference could be achieved if the merchant was voiced-over by a person who narrates educational or documentary programmes - like, for instance, Sir David Attenborough. Of course, this is only a suggestion of the authors of the present paper, as no dictionary exists which contains a list of people - whether they be voice-actors, historical figures, or others - and their intercultural one-to-one equivalents. 
The focus shall now be shifted to a folklore song which constitutes the third example of cultural differences between the original game and its localization into English. While two characters are on a hunt in the mountains after a forktail (a type of in-game dragonlike creature with a spike-covered tail - hence the name), Eskel, a friend of the main protagonist, starts singing: "Idom se łowiecki, idom dołu pyrciom; Juhasa nie widno, ino dzwonki zbyrcom" [lit.: There go the sheep, there go the sheep along a narrow mountain path, the shepherd is nowhere to be seen, the cowbells are ringing]. When Geralt asks about the song, Eskel replies that his mother used to sing it to him when he was little. As regards the song itself, it is a song from Polish folklore that tells about sheep that are roaming around unattended by a drunk highlander. In the English version of the game, however, Eskel sings something entirely different: "The old hen she cackled, and she cackled on the fence; The old hen she cackled, and she ain't cackled since". This song, on the other hand, was initially sung most frequently by African American slaves but evolved - given the fact that it describes an old hen that cackles a lot and, as she lays no eggs, ends up in a pot - into an African American children's song (Dabczynski and Phillips 2007). As may be inferred from the quotations, localizers decided to juxtapose an old Polish folk song with something that they believed to be a cultural equivalent thereof. Such an operation requires an extreme amount of caution, as it greatly alters the past and history of a given character, and therefore may not fit well in the narrative of the game: in this case Eskel's mother, who was in the source language version a Caucasian highland woman, becomes an African American slave from the regions of Texas.

The last example to be scrutinized pertains to the Semantic Layer and the localization of jokes and puns. Although the entire game is full of them, the usage of both the former and the latter is particularly apparent in the quest in which Geralt, in order to banish a phantom, eats magic mushrooms and starts talking to his horse Płotka (Roach). During one of their conversations Płotka tells him a joke: "Co powiedział ślepy koń przed wkroczeniem na tor wyścigowy?" [lit.: What did the blind horse say when he entered the race track?] and then she immediately answers her question with: "Nie widzę przeszkód. He he...! Się uśmiałam..." [lit.: I see no obstacles. Ha ha! I had a good laugh...]. Such word-for-word translation, however, would not work here, since the phrase "Nie widzę przeszkód" [lit.: I see no obstacles] constitutes an idiom which means something along the lines of "It is possible, I can do it". This joke would have been banal and unamusing, had it not been for the expression "Się uśmiałam" [lit.: I had a good laugh...] which is the real joke here, as it accounts for a part of the Polish idiom "koń by się uśmiał" [lit.: a horse would laugh]. Such an idiomatic expression perfectly fits the situation and works well as a commentary on the first joke, as it is generally used when one wants to say that something is not funny at all. Regarding the English localization of the joke, it was translated as follows: "Horse walks into a tavern, and the innkeep says: Hey, pal, why the long face? Hah!". Here too, the joke is rather banal, as the phrase "long face" can be interpreted literally as a reference to horses' physiognomy, and idiomatically as "why are you so sad?". That being said, the source and target language idioms have different linguistic implications, and therefore cannot be treated as idiomatic equivalents. What is more, the English version is slightly problematic due to the fact that, unfortunately, it lacks the pun that is present at the very end of the joke in the source text. 


\section{CONCLUSIONS}

The empirical considerations provided above show that the Semantic, Graphic and Iconic Representation, and Cultural Layers account for the most problematic and challenging stages in the localization process of cultural references, folklore and humour in Wiedźmin 3: Dziki Gon. As regards the Semantic Layer, sometimes faithful localization of idioms is, similarly to translation, not possible due to the fact that a particular source language idiomatic expression may not always have a direct one-to-one equivalent in a given target language. The joke analysed herein shows that a creative substitution of an idiomatic pun with a situational joke may still result, regrettably, in a loss of a comic effect. Additionally, the Graphic and Iconic Representation Layer may not infrequently also leave little room for linguistic manoeuvres because, as in the case of the ritual described, the target text needs to harmonize with the in-game characters' animations, behaviour, and the general setting of a given situation. Lastly, the Cultural Layer may be viewed as the most complex phenomenon, as it had to be taken into account in localization process of each and every example scrutinised herein. That being said, localization of cultural references requires from localizers not only vast amounts of cultural knowledge but also a great deal of caution, so as to avoid drastic alteration of certain elements of the game - like, for instance, the character's background and his past. Summing up, localization, especially in the case of video games, may be viewed as an extension of Nida's (1964) considerations on the notion of equivalence. As emerges from the analyses of the examples, localizers opted for dynamic rather than formal equivalence; namely they prioritized an accurate rendition of the meaning of the source text at the expense of strict adherence to the lexical and grammatical peculiarities thereof. Consequently, certain linguistic, humorous and cultural implications of the source texts are, unfortunately, not present in the target texts, but this seems to be a natural element or, rather, necessary evil - of the complex, multi-stage localization process of a video game. Of course, the above conclusions ought to be considered illustrative and treated as such, as they apply only to the material analysed herein. Therefore, the said conclusions ought to be verified against a more extensive corpus.

\section{REFERENCES}

Adiyia, Michael, and William Ashton. 2017. Comparative Research. Brandon University: Rural Development Institute.

Anastasiou, Dimitra, and Reinhard Schäler. 2010. "Translating Vital Information: Localization, Internationalisation and Globalisation". In Syn-thèses Journal 3, edited by Xanthippi Dimitroulia, 11-25. Greece: Aristotle University of Thessaloniki.

Barbour, Robert, and Alvin Yeo. 1996. "Bilingual/Multi-lingual Business Software: The Spreadsheet". In Proceedings of 1996 Information Systems Conference of New Zealand, edited by Philip J. Sallis, 63-71. Washington: IEEE Computer Society.

Bernal-Merino, Miguel, Á. 2014. Translation and Localization in Video Games: Making Entertainment Software Global. New York: Routledge.

Bourges-Waldegg, Paula, and Stephen Scrivener. 1998. "Meaning, the Central Issue in Cross-cultural HCI Design". In Interaction with Computers, edited by Dan Daiper, 287-309. London: Oxford University Press. 
Catford, John. 1965. A Linguistic Theory of Translation, London: Oxford University Press.

Chroust, Gerhard. 2007. "Software Like a Courteous Butler - Issues of Localization Under Cultural Diversity". In Proceedings of the ISSS 2007. The 51th Annual Meetingand Conference for the System Sciences. 858-873. Tokyo: Curran Associates.

Dabczynski, Adrew, and Bob Phillips. 2007. Basic Fiddlers Philharmonic: Old-Time Fiddle Tunes for Violin. USA: Alfred Publishing.

DePalma, Donald, A. 2006. "Quantifying the Return on Localization Investment". In

Perspectives on Localization, edited by Keiran J. Dunne, 15-36. Amsterdam: John Benjamins Publishing Company.

Gambier Yves. 2010. “Translation Strategies and Tactics". In Handbook of Translation Studies, edited by Yves Gambier and Luc van Doorslaer, 412-418. Amsterdam: John Benjamins Publishing Company.

Krishna, Sundar, Sundeep Sahay, and Geoff Walsham. 2004. "Managing Cross-cultural Issues in Global Software Outsourcing". Communications of the ACM 47(4): 62-66.

Lakoff, George and Mark Johnson. 2003. Metaphors We Live By. Chicago: University of Chicago Press.

Laxström, Niklas, Graham Wilcock, and Kristiina Jokinen. 2017. "Internationalisation and Localization of Spoken Dialogue Systems". In Dialogues with Social Robots: Enablements, Analyses, and Evaluation, edited by Kristiina Jokinen and Graham Wilcock, 207-220. Singapore: Springer Science+Business Media.

Lynch, Clove. 2006. "GMS Technology Making the Localization Business Case”. In Perspectives on Localization, edited by Keiran J. Dunne, 37-46. Amsterdam: John Benjamins Publishing Company.

Maumeviÿienė, Dainora. 2012. "Linguistic Insights into Localization”. In Translation and Reconfiguration of Power Relations: Revisiting Role of Context of Translation and Interpreting, edited by Beatrice Fischer and Matilde Nisbeth Jensen, 109-126. Berlin: LIT Verlag Münster.

Miller, Christopher. 2004. "Human-Computer Etiquette: Managing Expectations with Intentional Agents". Communications of the ACM 47(4), 30-34.

Munday, Jeremy. 2008. Introducing Translation Studies: Theories and Applications. New York: Routledge.

Nida, Eugene. 1964. Toward a Science of Translating: With Special Reference to Principles and Procedures Involved in Bible Translating. Leiden: E. J. Brill.

Schäler, Reinhard. 2007. "Localization". In Encyclopedia of Translation Studies, edited by Mona Baker and Gabriela Saldanha, 2, 157-161. New York: Routledge.

Schäler, Reinhard. 2008. "Linguistic Resources and Localization". In Topics in Language Resources for Translation and Localization, edited by Elia Yuste Rodrigo, 195-214. Amsterdam: John Benjamins Publishing Company.

Vierra, Kimberly and Brian Vierra. 2011. Vietnam Business Guide: Getting Started in Tomorrow's Market Today. Singapore: John Wiley \& Sons. 
AUTHOR'S BIO: Piotr Maziarz is a PhD student in Linguistics at the Institute of English Studies, University of Rzeszów. His doctoral dissertation capitalizes on comparative analysis of Polish and English conceptual metaphors in legal documents. His research interests include cognitive linguistics, contrastive linguistics and translation studies.

E-MAIL: piotr.maziarz.ur@gmail.com

AUTHOR'S BIO: Debora Onik is a PhD student in Literary Studies at the Institute of English Studies, University of Rzeszów. Her doctoral dissertation focuses on comparative analysis of three Polish translations of Beatrix Potter's children's tales. Her research interests encompass children's literature, folk literature and translation studies.

E-MAIL: d.onik@o2.pl 